\title{
Las elecciones de la Segunda República en Cuenca, el papel del Continuismo
}

\author{
Miguel Angel Ortega
}

Por razones obvias pocas veces la provincia de Cuenca ha despertado el interés de los historiadores. El abandono al que ha estado sometida esta provincia tradicionalmente marcada por el conservadurismo del comportamiento social y político de sus habitantes es mayor cuanto más reciente es el período histórico considerado, hasta el punto que, salvo para anotaciones marginales o referencias a circunstancias muy concretas, nada hay publicado sobre el período republicano conquense.

Sin embargo, en un momento como éste en el que están conociendo un importante auge las investigaciones locales parecía interesante, entre otras razones por lo mucho que se ha sobreseído, detenerse en esta parcela de la historia contemporánea española aun asumiendo el indudable riesgo de que, sin una adecuada estructuración de las investigaciones locales que rentabilice la suma de esfuerzos, fuera a ser el de quien esto firma un principio sin continuidad.

Por lo demás, la dinámica interna de la provincia conquense es bien sugestiva porque su paisaje ( $y$, por ende, su dedicación económica y la percepción de la realidad social y política de sus habitantes) no es uniforme y aglutina tres comarcas diferentes: la Serranía, la Alcarria y la Mancha. A lo que aquí interesa se trata más bien de dos grandes espacios que, en líneas generales, pueden repartirse el espacio provincial a partes iguales: el manchego, y el serrano-alcarreño. Cada uno de estos espacios es radicalmente distinto al otro. La Mancha se presta a la organización de cultivos extensivos de cereales y vid en manos muchas veces de terratenientes que perpetúan el reparto repoblador del Medievo (confirmado, por lo demás, por el proceso desamortizador del xIX) y la Serranía, por el con- 
trario, ofrece un aspecto montañoso donde la ganadería, la explotación forestal, determinadas formas de propiedad comunal y el cultivo intensivo de productos de huerta constituyen la principal actividad económica. Correlativamente, La Mancha, atravesada además por dos vías de comunicación que ya en tiempos republicanos eran importantes ejes terrestres (la $\mathrm{N}$-III y la N-301) está más poblada y su demografía se caracteriza por el agrupamiento en núcleos de mayor tamaño. El número de municipios en la Serranía es más elevado pero su contingente demográfico es bien escaso.

De dos realidades tan diferentes (la una entroncando con el sur de la península y la otra con las estructuras norteñas) cabía esperar resultados también diferentes.

Aún más, en una provincia a la que se le suponen una notable lentitud de adaptación a los cambios históricos, era de esperar la pervivencia de ciertos usos caciquiles manifestados de una u otra forma.

Por último, también en Cuenca era muy interesante estudiar hasta qué punto el ciudadano del medio rural se comportaba de forma distinta al del medio urbano, aunque éste fuera tan escasamente arquetípico de lo urbano.

Tras la investigación realizada en torno a los procesos electorales republicanos en Cuenca, se pueden extraer las siguientes conclusiones generales, que responden a esas y otras cuestiones.

\section{Los orígenes del movimiento republicano fueron tímidos y tardíos y tuvieron en sus principios un escaso poder de penetración social}

El primer comité (titulado de Unión de Izquierdas) se constituyó en Carrascosa del Campo en febrero de 1930 tras que en Tébar y Huete se hubiesen comunicado adhesiones a la Alianza Republicana. Cuando el comité decide denominarse republicano es ya el mes de junio y por entonces aglutinó al 20 por 100 del electorado.

Posteriores comités se constituyeron en Torrejoncillo del Rey, San Clemente, Horcajo de Santiago, Montalbo, Pozorrubio, Villarta, Caracenilla, Paracuellos de la Vega, Mira, Landete, Hontanaya, Casas de Guijarro, Cardenete, Tébar, El Provencio, Cañada del Hoyo, Tarancón, Atalaya del Cañavate, Casasimarro, Huete, Altarejos y Valverde del Júcar. En la lista es 
notorio que La Mancha, más cercana a las grandes vías de comunicación interprovinciales y con una economía de base agraria en la que estaba fuertemente arraigada la figura del jornalero acapara la mayor parte de los nombres, coincidiendo además agrupaciones de pueblos limitrofes, lo que puede explicar cierto sistema de adhesión de voluntades; junto a ella, dos pueblos alcarreños (Huete y Caracenilla) ubicados también en el itinerario del ferrocarril Madrid-Cuenca, y algunos núcleos de la llamada Sierra Baja, próximos al límite de la provincia con Valencia.

Ciertas variables, pues, explican un afloramiento que dejaba absolutamente al margen a todo el tercio norte de la provincia (con excepción de Tragacete, acaso el más próspero de los pueblos serranos), el de los municipios alcarreños y de la Serranía que, en algunos casos, colindan con las provincias de similar perfil socioeconómico de Guadalajara y Teruel, y en todo son ejemplos de un subdesarrollo completo y un aislamiento inveterado.

En la capital, el Partido Republicano se constituye en octubre de 1930 con una nómina de noventa personas. La diversidad ideológica entre ellas abarca prácticamente todo el espectro del republicanismo, desde el derechista hasta el radical-socialista. Pese al retraso con respecto a algunos puntos de la provincia en su nacimiento, la mayor militancia republicana se localizará, en adelante, en la capital.

\section{La caracterización sociológica del republicano es diferente a la del republicano de los municipios de la provincia}

El primero pertenece a la clase dirigente. Altos funcionarios municipales, profesionales liberales, industriales, docentes... son las profesiones predominantes entre los cuadros del Partido Republicano y seguirán siéndolo en las formaciones posteriores.

Electra, periódico adicto a la causa republicana, afirma que los miembros de comités republicanos en la provincia también responden a esa extracción socio-económica, pero mis investigaciones al respecto contradicen esa información y apuntan a que el militante de la Cuenca rural solía ser un hombre dedicado fundamentalmente a oficios manuales de baja consideración social. Este dato explica cómo un pueblo de bajo nivel cultural es atraído más fácilmente a la hora de votar por unos partidos, como los de derechas, que contaban por lo general con personalidades de prestigio en sus filas, bien porque fueran caciques locales bien por ser gentes - simultánea o independientemente de ello- de más elevada consideración socio-profesional. 


\section{Durante el quinquenio se deterioró el nivel de vida del obrero, pero es difícil atribuir a esa causa una reorientación decidida del voto}

Se ha realizado un estudio de la evolución de precios y salarios en Cuenca capital que viene a confirmar que aquéllos se incrementaron y éstos prácticamente se mantuvieron estables. Sobre el nivel de precios existen diversas lecturas, aunque en general son coincidentes. Las fuentes locales indican una subida que, exceptuando la cresta de 1934, se sitúa en algo más de un 11 por 100 en todo el periodo. Según los datos que aparecen en los boletines del Ministerio de Trabajo no existe tal subida y ni siquiera se aprecia una línea constante en la evolución del indicador. De los profundos dientes de sierra que en ella se forman se extraen, sin embargo, dos conclusiones: que existe una subida relativa en relación con el nivel de 1931 y de los tres años anteriores, y que esa subida se debe, fundamentalmente, a una cresta pronunciada a lo largo de 1934 que en los meses sucesivos será difícil recuperar. Por otro lado, la media de precios de las capitales de provincia establece que los alimentos básicos sólo superaron el nivel de 1931 en marzo de 1932, lo que reafirma el deterioro de la renta de los obreros de la capital conquense. Por otro lado, los salarios apenas experimentaron variación alguna. La ligerísima pendiente de ascenso, que en el supuesto de los salarios máximos no llega a un 1 por 100 y en el de mínimos apenas supera el 3 por 100 se debe, además, a subidas puntuales en muy concretas especialidades: ebanistas, albañiles, pintores y peones braceros.

La traducción electoral de estos resultados es, sin embargo, difícil de precisar por el escaso manejo que de estas estadísticas se hacía por entonces (la prensa no recoge alusiones precisas y los candidatos tampoco suelen esgrimirlas) y sólo en 1936 podría columbrarse una orientación del voto en el que alguno de los componentes fuera éste. Debe señalarse que si ello se pudo traducir en una percepción negativa del hecho republicano por las capas sociales proclives a su defensa, lo fue más de un modo subjetivo que objetivo.

\section{La izquierda política se caracterizó por su falta de unión y su es- casez de cuadros}

Elección por elección se constatan ambos extremos. En las municipales de abril de 1931, pese a que podía considerarse la existencia de un acuerdo tácito desde los últimos meses del año anterior, la candidatura de la conjunción republicano-socialista comienza a definirse en el mes de marzo, cuando, por entonces, se decide acudir a los comicios. 
Para las constituyentes, tres de los cuatro miembros de la canditatura conjuncionista fueron de la Derecha Liberal Republicana y uno solo socialista.

Es conocido que para las elecciones de 1933 ya se había roto el acuerdo de dos años antes. En Cuenca, además, no se presenta nada más que una candidatura radical-socialista. Un año antes, con motivo de unas elecciones parciales al Ayuntamiento de la provincia, ya los socialistas habían abandonado el escenario y sólo se presentaron candidatos republicanos.

La CNT, por su parte, que desplegó una actividad importante, previsiblemente mayor que UGT (a pesar de que geográficamente Cuenca es zona de influencia ugetista), y fue responsable de algunos de los episodios más viscerales de la época, no alcanzó una buena organización en Cuenca hasta 1933. Es precisamente en las elecciones del mes de noviembre de ese año cuando los distritos electorales más caracterizadamente obreros de la capital, registran las mayores cifras de abstención, que llegan incluso al 56,4 por 100 (más destacado cuanto en 1931 se registraron participaciones de casi el 80 por 100). Sin embargo, no es fácil atribuir todo este porcentaje de inhibición a la propaganda cenetista (que llegó a preocupar a las derechas seriamente) porque la ausencia de candidatos socialistas pudo retraer por sí misma ese voto.

\section{La derecha tradicional tuvo una respuesta varia al cambio de régimen}

En efecto, nombres clásicos de la Monarquía desaparecieron tras los primeros meses de República. Instalados en diversas concejalias, fueron dimitiendo muchos de ellos, la mayor parte aduciendo razones médicas y alguno declarándose amenazado y sin libertad para exponer sus opiniones. Otros desaparecieron y volvieron a la política en 1933 (caso de Correcher) o en 1936 (Cayo Conversa) con poco éxito. Finalmente, un tercer grupo se adaptó a la nueva situación y se mantuvo en activo en partidos de derecha.

\section{Cuenca fue cancha política para candidatos ajenos a la provincia}

La cercanía de la provincia a la capital de España permitió que varios políticos de Madrid se presentaran por Cuenca. El fenómeno de los cuneros fue frecuente durante toda la República y habla de la escasa fuerza de los partidos políticos locales, en este caso de las derechas, por quien entraban en liza aquellos nombres. El caso más característico era el de 
Fanjul, ligado a la provincia desde tiempos de la Monarquía en que fue destinado a la plaza, y que "apadrinó" la llegada a Cuenca de Antonio Goicoechea, líder de Renovación Española que no encontraba acomodo en otras listas. A estos nombres hay que sumar los de Carlos Blanco - Marín Lázaro en 1931 y Primo de Rivera y Franco (que finalmente no se presentó) en 1936. Otros nombres como el de Sierra respondían a personas nacidas en la provincia pero desvinculadas de ella desde hacia tiempo.

Considerada la provincia como una circunscripción de fácil acceso para la derecha, la imposición de un candidato a las agrupaciones locales aseguraba el acta a candidatos que en otras provincias tendrían mayores dificultades.

\section{Las campañas electorales están basadas fundamentalmente en temas nacionales}

Desde que en las proximidades de 1931 los nombres de los capitanes Galán y Hernández eran argüidos como bandera de las reivindicaciones republicanas, hasta mayo de 1936 en que Indalecio Prieto pronunció un discurso conocido en vísperas de la segunda vuelta de las elecciones, todas las campañas giraron en torno a la política nacional.

La prensa dictada desde Madrid reproducía críticas de alcance global y la de carácter local se ocupaba también de aquellos temas de forma prioritaria. La política conquense se trataba con poco interés y casi todas las apreciaciones buscaban la crítica a los presupuestos municipales sin que se dejen traslucir más datos que los enfrentamientos entre la prensa de distinta tendencia.

Los mítines de los candidatos tanto en la capital como en la provincia obviaban anotaciones de interés inmediato a los oyentes y no pocas veces su oratoria y su mensaje queda lejos de las posibilidades de comprensión del público.

\section{La prensa conoció muchas iniciativas pero su capacidad de crea- ción de opinión sería bastante limitada}

Ya con anterioridad existian algunas publicaciones periódicas pero en estos años se multiplicaron. Se han contabilizado doce periódicos confeccionados en la capital (Electra, República, La Libertad, El Día de Cuenca, La Voz de Cuenca, La Opinión, El Centro, El Defensor de Cuenca, Boletín 
Conquense, La Voz del Catecismo, Magister y Heraldo de Cuenca), la mayoría de ellos, aunque no todos, como se deduce de los títulos, de información predominantemente política, y se sabe de la existencia de otros tres en la primera población de la provincia, Tarancón, si bien sólo se sabe el nombre de uno de ellos, Vértice.

Como en tantos otros lugares los periódicos de intencionalidad política difieren de lo que hoy se entiende por tales. Se trata de dos planchas de cuatro hojas cada una que se ocupan prioritariamente de emitir un mensaje partidista y panfletario por completo. Los propietarios suelen ser hombres públicos y se dan casos de publicaciones nacidas para apoyar determinada candidatura que desaparecen pasado el período electoral.

Su influencia entre el electorado es otra cuestión a debatir. Sus contenidos se difundirían en reuniones por lo que la transmisión oral podría paliar el inconveniente declarado de un 18,21 por 100 de analfabetos en 1930 en Cuenca capital (la cifra se eleva al pensar en los analfabetos funcionales y al trasladarla a la provincia), pero la difusión que tendrían en la provincia habría de ser forzosamente menor. De hecho, los periódicos se convierten en voceros de la actividad detectada en los municipios de la circunscripción y las referencias que en ellos aparecen hacen sospechar que su papel como movilizador de voluntades habría de ser más bien escaso, reducido a una élite local en muchos casos previamente concienciada.

\section{Perviven durante todo el período usos y comportamientos caci- quiles}

El análisis de los resultados de las distintas elecciones revela, a la vista de los mapas, que determinados candidatos ejercen influencias muy fuertes sobre zonas concretas y que son atribuibles necesariamente a la herencia vigente del caciquismo de los candidatos. El caso más claro es el del general Fanjul, que domina en todos los comicios una buena parte de los pueblos alcarreños y la zona en torno a la localidad de San Lorenzo de la Parrilla, cuna del maurismo, en el que estuvo inscrito, años atrás. Los candidatos de derechas consiguen con frecuencia victorias parciales por este procedimiento y lo hacen, probablemente favorecidos por la influencia del general, en pueblos serranos y alcarreños que están casi vetados para la izquierda.

Similar es el caso de Cuartero en Las Mesas, donde fue alcalde y suele conseguir buenos resultados a pesar de que la zona manchega en la que se sitúa era más propicia a recibir más influencias. 
El socialismo tuvo en Aurelio Almagro en las elecciones de 1931 un ejemplo similar. Médico rural que ejercía la profesión en la comarca del Campichuelo, su nombre obtuvo la mayoría de los votos en todos los pueblos de su demarcación médica.

Las poblaciones vecinas a Uclés se constituyen, en 1931, en una cuña de votos fanjulistas en medio de un espacio ampliamente dominado por la candidatura oficial. Probablemente no sea ajeno a este resultado la existencia en Uclés de un monasterio que se constituiría en el órgano rector de la vida - casi en un sentido feudal- de su pequeña comarca y que favorecería un voto marcadamente religioso y de orden.

Esta realidad ayuda a explicar la orientación predominantemente derechista del electorado conquense. Hay que pensar en una provincia en la que el animal de carga era el medio de transporte más habitual por unas vías de comunicación verdaderamente penosas que depararían, en consecuencia, el virtual aislamiento de numerosos pueblos. No puede descartarse que para una proporción quizás no mayoritaria, pero desde luego tampoco desdeñable, de electores, no hubiese sobrevenido ningún cambio de régimen. $A$ otros muchos que sí tendrían el conocimiento de esa transformación se les escaparía, en cambio, su verdadero significado.

\section{En la capital, por el contrario, la dinámica electoral es diferente y el voio responde más a unas tipologías de comportamiento que estarian en función de la extracción social del grupo considerado}

La capital se caracteriza en todos los comicios por poseer mayor madurez política. Aquí sí es posible caracterizar sociológicamente cada distrito y cada sección electoral y establecer zonas urbanas obreras en su práctica totalidad, otras dominadas por las clases medias y otras característicos lugares de habitación de los sectores más influyentes de la sociedad conquense, y los resultados serán siempre coherentes con el voto que se espera de cada grupo definido y, especialmente, en el caso de los distritos de jornaleros.

No obstante, existen notables excepciones. La sección conocida en la época como la "caverna" está poblada fundamentalmente por jornaleros y es importante el número de los que se ocupan del servicio doméstico. También es la ubicación de los conventos, buen número de iglesias, el Obispado y el seminario. El número de electores del clero es, lógicamente, reducido en términos comparativos y, sin embargo, esta sección vota siempre por las derechas como consecuencia de la influencia ejercida por ese sector de población. 
Si esto ocurría en la capital, no menos puede esperarse de amplísimos colectivos de zonas rurales allí donde el párroco tuviese el suficiente poder o la necesaria ascendencia sobre la feligresía.

Otro fenómeno similar se detecta con la candidatura de Correcher, importante industrial maderero y empleador de mano de obra capitalina, que consigue, a pesar de presentarse en listas de ubicación centrista, el 57 por 100 de los votos en una sección en la que el 94 por 100 del censo responde a la clasificación de jornalero.

\section{Las elecciones no fueron libres}

Mucho se ha escrito sobre la pureza de las elecciones de la II República y del importante avance logrado en cuanto a la limpieza de los comicios electorales. Habitualmente se duda de que las constituyentes de 1931 sean un paradigma de corrección pero no se suele polemizar sobre las demás.

Las investigaciones llevadas a cabo en la provincia de Cuenca confirman que no siempre existieron coacciones pero en absoluto permiten afirmar que los cuatro encuentros electorales fueron absolutamente limpios.

Lo serían en la capital porque ninguna fuente pone en duda que las cosas ocurrieran de otro modo (ni siquiera en mayo de 1936, con la presencia por las calles de juventudes de ambos signos dispuestos a "defender" el orden, cabe pensar en manipulaciones) pero no en la provincia, y sobre todo en las localidades más pequeñas, en donde me consta que las manipulaciones, las compras de votos y los chalaneos eran moneda común. Aparte de la narración de estos hechos por testigos presenciales (los delegados de los partidos negociaban con los miembros de la mesa y con otros delegados, si los habia, el precio de la urna), un vistazo a los resultados es suficiente para constatarlo. En las elecciones de 1931 puede asegurarse sin demasiado riesgo de error que en 53 municipios - sobre un total algo inferior a los trescientos- se produjeron amaños. En noviembre de 1933 no es tan fácil identificar los casos pero no se pierden las secciones en las que una candidatura obtiene todos los votos. Perdidas las actas de la primera vuelta de 1936, existe constancia de que la segunda vuelta la situación se reprodujo, y no ya sólo para secciones de reducido censo. En este caso la mayor responsabilidad de amaño recayó en el Frente Popular. En la mayoría abrumadora de los otros, en las derechas.

El hecho de que la abstención sea mayor por sistema en la capital que en la provincia confirma este punto de importancia capital. No es de recibo 
que el electorado más formado políticamente, el urbano, opte por abstenerse más que el de la provincia, a menos que éste (obviamente más al margen de la política) no llegue a votar y se arregle su participación o la haga bajo coacciones o manipulaciones.

\section{La capital vota siempre más izquierdista que la derecha}

Dos circunstancia lo explican. Una, que, en un ambiente más politizado y al que llegan con más facilidad los medios de comunicación, se acepte mejor el cambio de régimen en la medida que se entiende como progreso, y se abracen mejor los idearios obreristas, que significan ruptura con esquemas mentales tradicionales no ya en lo económico sino más en lo social y religioso. Otro, que es un resultado lógico de un colectivo más alejado de presiones externas a la lógica electoral.

Las elecciones municipales de abril de 1931 depararon un triunfo de la conjunción republicano-socialista en la capital caracterizado por:

1. Las dudas y la roma participación de la conjunción, que acudió a los comicios con sólo quince candidatos, lo que suponía en la práctica poco menos que abandonar la posibilidad de conquistar la alcaldía, habida cuenta de que la corporación la formaban veintiún miembros.

2. El estrecho margen de diferencia, que fue de 312 votos sobre 8.586 emitidos.

3. La mayor penetración social de los republicanos con respecto a los socialistas, que obtuvieron menos votos que sus coaligados en todos los casos, acaso porque la imagen pública de los hombres del PSOE fuera peor que la de los radical-socialistas.

4. La mayor cohesión del voto conjuncionista, que se decantó en los barrios obreros por sus candidatos de forma más clara (porcentajes del 85 y 72 por 100) que los partidarios del continuismo por los suyos (60 y 70 por 100 en los mejores casos).

5. En la misma línea, mayor participación electoral de los barrios obreros. Las cinco secciones con menor porcentaje de jornaleros entre sus censados arrojaron una abstención del 42,79 por 100 y las cinco secciones con más jornaleros registraron una inhibición del 36,43 por 100. 
6. Abstención identificada sobre todo en las clases medias, sometidas a la duda de aceptar la incógnita previsible del cambio de régimen o de mantener una situación deteriorada que tampoco terminaba de responder a sus intereses y convicciones.

7. Un resultado contemporizador: el alcalde resultó ser el único republicano de derechas que figuraba en la coalición.

En la provincia los resultados favorecieron a los monárquicos. Nada menos que 846 concejales monárquicos sólo por el artículo 29 colocaban a Cuenca en la primera de las provincias según este criterio. La inexistencia de clases medias, la poca formación política del conquense del primer tercio de siglo, su bajísimo nivel cultural y la poderosísima influencia de caciques locales del viejo estilo constituyen un arco de motivaciones reciprocamente imbricadas que explican un resultado tan concluyente. Incluso en Carrascosa del Campo, en donde vence la conjunción por el mismo artículo, la filiación es moderada: de los diez concejales, tres se definen como agrarios; dos, republicanos solamente; uno, socialista y uno monárquico.

De las elecciones constituyentes del mismo año 1931 puede concluirse que:

1. Como ya se ha dicho, no fueron libres.

2. Se marca las pautas generales de comportamiento para futuras elecciones.

3. Los manejos electorales se detectan sobre todo en las zonas más deprimidas, en las comarcas de la Sierra y la Alcarría, y resultan especialmente destacables tanto la repetición del nombre de Fanjul en muchos de los municipios afectados, como los empates producidos entre los candidatos de diferentes listas, resultado, sin duda, de "negociaciones" ilegales.

4. En la candidatura conjuncionista, a diferencia de lo que ocurría a nivel nacional, la Derecha Liberal Republicana está sobrerrepresentada, con tres miembros por un solo socialista. En realidad, ninguna de las dos fuerzas estaba en proporción con la adscripción política del electorado. El partido más fuerte era por entonces el radical-socialista. Por lo demás, existen diferencias diametrales con respecto a la composición de la candidatura para las elecciones municipales de la capital. Cabe pensar que en 
este caso las agrupaciones locales pudieran decidir por si mismas las listas y que a la hora de proponer los candidatos a diputados se tuviesen que aceptar órdenes. La intervención del Gobernador civil, Manuel García Rodrigo, miembro de Derecha Liberal Republicana, sería decisiva.

5. La participación fue elevadísima ( 80 por 100$)$ incluso traspasada a los parámetros actuales. En la capital la participación es sólo del 66 por 100.

6. Los resultados muestran una victoria aplastante de la candidatura oficial, que triunfa en 164 de los 289 municipios computados. Pueden definirse "dominios lineales" (siguiendo el trazado de vías de comunicación) y "dominios espaciales" (en torno a un núcleo de población más importante, una pequeña cabecera de comarca) en función de la uniforme distribución de triunfos electorales de las distintas fuerzas litigantes. En muchos casos no son sino espacios "caciquiles".

7. Los resultados de la capital ofrecen una victoria más amplia de la candidatura oficial (un 70 por 100 de los votos emitidos lo fueron en su favor frente al 52,9 por 100 del conjunto de la provincia). Con respecto a las elecciones municipales se observa un incremento importante de los votos socialistas en función del ascendiente popular del candidato, Aurelio Almagro.

Las elecciones municipales de abril de 1932, convocadas por necesidades de renovación de la corporación, una vez que la abandonaron la tercera parte de los concejales, la mayoría de ellos de derechas, no registra movimientos previos y se realiza en medio de la apatía general. A ello pudo contribuir que la alcaldía no cayera en manos de las derechas por muy favorable que les fuese el resultado. Sin embargo, no por eso debe minusvalorarse su alto poder indicativo en relación con el generalizado estado de decepción existente tras un año de República.

La victoria correspondió, por seis concejales a uno, a la Asociación Ciudadana Agraria, embrión de la futura CEDA. El concejal republicano saldría elegido por necesidades matemáticas. Los socialistas no presentaron candidato. El análisis de los resultados sumió en la autocrítica a los sectores derrotados, pero a ello no le siguió un replanteamiento, ni siquiera a nivel local, de las estrategias políticas.

Sólo una sección electoral mantuvo la primacía del voto republicano y cambió la orientación del voto de todo un distrito que ahora se inclinaba por los agrarios. La participación fue del 60 por 100. 

tos:

La elección general de 1933 se puede resumir en los siguientes pun-

1. Se presentan tres candidaturas: la Unión de Derechas Agrarias, que incluye a hombres poco favorables de la República, como el líder de Renovación Española, Antonio Goicoechea; los antiguos candidatos por Acción Nacional, Cuartero y Gosálvez; y el carismático general Fanjul; los radicales, beneficiados de la descomposición de la Derecha Liberal Republicana; y los radical-socialistas, que presentan figuras de escaso relieve político en la provincia. EI PSOE no tiene ningún candidato elegible en estos comicios.

2. La campaña adquirió tonos agresivos, especialmente en el lenguaje adoptado por la derecha para criticar al PSOE, a los radicales y a la CNT sucesivamente, conforme se temía que un posible fracaso dependiera de cada una de esas fuerzas.

3. La victoria de las derechas fue total, con un 61,56 por 100 de los sufragios emitidos a su favor. Los dos puestos de las minorías los ganó el Partido Radical con un 25,03 por 100 de los votos. Los radical-socialistas sólo fueron votados en un 13,41 por 100 de los casos.

4. La participación fue del 72,84 por 100 . La cifra justifica que la abstención propugnada por la CNT no fuese la responsable de que Cuenca se convirtiese en una de las provincias más derechizadas del panorama político español. La interpretación de los resultados debe pasar, pues, por estimar que votos de los emitidos en 1931 en favor de la DLR no implicaban, en rigor, votos derechistas ante la ausencia de una candidatura de tal tendencia más convenientemente presentada.

5. Por otro lado, la izquierda fue incapaz de ofrecer al agro conquense unos candidatos socialistas o republicanos que hubiese mantenido su prestigio durante los dos primeros y polémicos años de la República. La derecha disponía de todas las carencias de su rival y podía permitirse considerar la circunscripción como un coto propio en el que imponer una candidatura con nombres de alcance nacional y esgrimirla como una garantia de prestigio.

6. Sólo en setenta municipios no obtiene la mayor parte de los sufragios la derecha, y éstos aparecen bastante dispersos, con especial incidencia en el flanco oriental de la provincia, curiosamente donde el voto republicano en 1931 había sido más vacilante. 
7. En la capital la participación fue del 59,79 por 100 , seis puntos menor que la anotada en 1931. En general, las cifras más altas corresponden a las secciones de voto más derechista en 1931, con un aumento de hasta 10 puntos porcentuales con respecto a aquella consulta. El distrito de composición social más baja aumenta su abstención en 14,40 puntos en relación con las elecciones de 1931. El obrero más izquierdista, posible afiliado o simpatizante de la CNT, se retrae, pero el menos concienciado políticamente opta por votar un nombre conocido, como el de Correcher.

8. La diferencia que existe entre la provincia y la capital en la orientación de voto está claramente expresada en el cuadro:

\begin{tabular}{lll}
\hline $\begin{array}{c}\text { Orientación } \\
\text { del voto }\end{array}$ & $\begin{array}{c}\text { Porcentaje } \\
\text { Provincia }\end{array}$ & $\begin{array}{c}\text { Porcentaje } \\
\text { Capital }\end{array}$ \\
\hline Derecha & 61,56 & 50,52 \\
Centro & 25,03 & 71,48 \\
Izquierda & 13,41 & 18,00 \\
\hline
\end{tabular}

A las elecciones de febrero de 1936 el Frente Popular presentaba dos candidatos de Izquierda Republicana y otros dos del PSOE, una composición que parece se adecuaba más a la fuerza real que tenían las agrupaciones en cuanto a su número de afiliados. Sin embargo, la observación de mapas electorales anteriores demostraba que en el caso que el votante tomó una decisión colectiva republicana, ésta se orientó hacia el moderantismo.

La derecha acude con un bloque para ganar por las mayorías y por las minorías, y en su lista aparece $\epsilon$ nombre de Sierra, candidato denostado en 1933 por sus ahora compañeros, y el de Casanova y Gosálvez, enemigos en tiempos de la Monarquia.

La tercera fuerza es el portelismo, representada por Mendizábal y Correcher.

Los resultados fueron favorables en todo a las derechas, que colocaron a sus seis candidatos aunque pierden 22.000 votos. La izquierda creció, a su vez, 17.000 votos. Todo ello con una participación del 75 por 100 . 
Impugnados los resultados, se tuvo que recurrir a una segunda vuelta cuyas vicisitudes son conocidas porque ocuparon el centro de la política nacional del momento. La discusión en Cortes, los nombres de Franco y Primo de Rivera, el discurso de Indalecio Prieto... Todo este proceso llevó a una modificación en los nombres de las candidaturas que acudieron pero, a lo que interesa, a modo de resumen, puede concluirse lo siguiente:

1. Ganó el Frente Popular con casi 70.000 votos mientras el Bloque Nacional se detenía en 48.000 (Primo de Rivera, cuyos datos no se computaron porque se declaró en vísperas de la elección que no era correcta su participación en los comicios, obtuvo 43.000 votos).

2. El análisis personal de cada una de las actas revela que las elecciones fueron una farsa en gran número de poblaciones. Las corruptelas serian sobre todo, pero no únicamente, imputables al Frente. De todas maneras, buena parte de los municipios que habían demostrado un grado de conservadurismo más o menos acentuado, mantienen el carácter de su voto y, a la inversa, el Frente Popular consiguió la gran mayoría de votos favorables en pueblos que en algún proceso electoral anterior habian demostrado cierta tendencia cuando menos republicana.

3. En la capital, de mayoría frentepopulista, la abstención es un factor fundamental. En las mesas siempre más inclinadas a la derecha es altísima, hasta llegar a un 56,8 por 100; al contrario, en las de voto proclive a la izquierda se constata una disminución directamente proporcional a la intensidad que en otras elecciones tuvo ese voto, hasta llegar a contabilizar una participación del 94,76 por 100 .

4. La diferencia entre el candidato más votado de cada bloque fue de algo más de 700 votos, lo que no puede sino confirmar que las izquierdas tenían un tope bien definido en la ciudad, que no fue superado ni aun en las circunstancias más favorables. 